\title{
Caution! Analyze transcripts from conditional knockout alleles
}

\author{
Shao H. Yang - Martin O. Bergo - Emily Farber • \\ Xin Qiao · Loren G. Fong · Stephen G. Young
}

Received: 18 September 2008/ Accepted: 27 November 2008/Published online: 18 December 2008

(C) The Author(s) 2008. This article is published with open access at Springerlink.com

\begin{abstract}
A common strategy for conditional knockout alleles is to "flox" (flank with loxP sites) a $5^{\prime}$ exon within the target gene. Typically, the floxed exon does not contain a unit number of codons so that the Cre-mediated recombination event yields a frameshift and a null allele. Documenting recombination within the genomic DNA is often regarded as sufficient proof of a frameshift, and the analysis of transcripts is neglected. We evaluated a previously reported conditional knockout allele for the $\beta$-subunit of protein farnesyltransferase. The recombination event in that allele-the excision of exon 3-was predicted to yield a frameshift. However, following the excision of exon 3, exon 4 was skipped by the mRNA splicing machinery, and the predominant transcript from the mutant allele lacked exon 3 and
\end{abstract}

S. H. Yang - E. Farber - X. Qiao - L. G. Fong ·

S. G. Young

Department of Medicine, David Geffen School

of Medicine, University of California, Los Angeles, CA 90095, USA

S. G. Young $(\bowtie)$

Department of Human Genetics, David Geffen School of Medicine, University of California, 650 Charles E. Young Dr. South, Los Angeles, CA 90095, USA

e-mail: sgyoung@mednet.ucla.edu

M. O. Bergo

Wallenberg Laboratory, Institute of Medicine,

Sahlgrenska University Hospital, Gothenburg, Sweden exon 4 sequences. The " $\Delta$ exon 3-4 transcript" does not contain a frameshift but rather is predicted to encode a protein with a short in-frame deletion. This represents a significant concern when studying an enzyme, since an enzyme with partial function could lead to erroneous conclusions. With thousands of new conditional knockout alleles under construction within mouse mutagenesis consortiums, the protein farnesyltransferase allele holds an important lesson-to characterize knockout alleles at both the DNA and RNA levels.

Keywords Protein prenylation - Farnesylation · Prelamin A - HDJ-2 - Knockout mice

\section{Abbreviations \\ Fntb Farnesyltransferase \\ FTI Farnesyltransferase inhibitor \\ MEF Mouse embryonic fibroblast}

\section{Introduction}

In preparing a conditional knockout allele, loxP sites are typically inserted into different introns of a target gene ("floxing" an exon or exons) (Kühn et al. 1995; Rajewsky et al. 1996; Schwenk et al. 1995). With the expression of Cre recombinase, the exon(s) of the gene is removed, resulting in a knockout allele. Typically, care is taken to "flox" an exon without a 
unit number of codons (i.e., an exon where the number of nucleotides in the exon is not evenly divisible by three) so that the recombination event yields a frameshift. A frameshift is important for creating a null allele (Hasty et al. 2000). Other considerations relevant to producing a null allele have been reviewed by Hasty et al. (2000).

A conditional knockout allele for Fntb, the gene encoding the $\beta$-subunit of protein farnesyltransferase (FTase), was reported by Mijimolle et al. (2005). FTase catalyzes the farnesylation (covalent attachment of a 15-carbon isoprenyl lipid) of proteins carrying a carboxyl-terminal CaaX motif (Casey and Seabra 1996). In Mijimolle's Fntb conditional knockout allele (Mijimolle et al. 2005), exon 3 (73 bp in length) was flanked by loxP sites. As expected, the expression of $\mathrm{Cr}$ recombinase excised exon 3, and that recombination event was well characterized at the genomic DNA level (Mijimolle et al. 2005). The excision of exon 3 was predicted by Mijimolle et al. (2005) to yield a frameshift and a null allele, but transcripts from the allele were not analyzed.

Without question, the Cre-mediated excision of exon 3 reduced FTase activity. Germline homozygosity for the recombined allele prevented normal embryonic development, and fibroblasts homozygous for the mutant allele had reduced FTase activity (Mijimolle et al. 2005). On the other hand, several features of Mijimolle's study (Mijimolle et al. 2005) were unexpected. For example, in homozygous knockout fibroblasts, H-RAS remained associated with membrane fractions (Mijimolle et al. 2005). That was peculiar because the association of H-RAS with membranes is utterly dependent on protein farnesylation (Berzat et al. 2005, 2006; Chenette et al. 2005; Takahashi et al. 2005). The prenylation of another farnesylated protein, HDJ-2, was only partially blocked in their homozygous Fntb-deficient fibroblasts (Mijimolle et al. 2005). Also, the Fntb knockout had no effect on tumorigenesis, while FTase inhibitor drugs retard tumor growth (Barrington et al. 1998; Omer et al. 2000).

In this study, we examined the Fntb allele generated by Mijimolle et al. (2005). We found that the predominant transcript produced by the mutant allele did not contain a frameshift but rather encoded a protein with a short in-frame deletion.

\section{Materials and methods}

Genetically modified mice

Mice harboring an Fntb conditional knockout allele $\left(F n t b^{\text {lox }}\right)$ and a fully recombined knockout allele $\left(F n t b^{\Delta}\right)$ (Mijimolle et al. 2005) were obtained from the Fundación Centro Nacional De Investigaciones Oncológicas Carlos III. Mice were genotyped by PCR with oligonucleotide primers 5'-CTGGAGGCTGG GAAGCTGGA- $3^{\prime}$ and $5^{\prime}$-GCCTAAGAGCCGTGT GGGGGT- $3^{\prime}$. The wild-type allele yielded a 1,940 bp fragment; the $F n t b^{\text {lox }}$ allele, a 907-bp fragment; the $F n t b^{\Delta}$ allele, a 557-bp fragment.

Fibroblasts from $F n t b^{\text {lox/ } \Delta}$ embryos were obtained as previously described (Todaro and Green 1963). Mouse embryonic fibroblasts (MEFs) (80\% confluent) grown on 6-well plates were infected with $\mathrm{Cre}$ adenovirus $\left(20 \mu \mathrm{l} / \mathrm{well}, 3 \times 10^{10} \mathrm{pfu} / \mathrm{ml}\right.$, Gene Transfer Vector Core, University of Iowa), and cells extracts were prepared 5 days later. In some experiments, cells were treated with $\mathrm{Cre}$ adenovirus only once. A single treatment with $\mathrm{Cre}$ adenovirus generally did not lead to $100 \%$ complete recombination; however, those experiments were nevertheless useful because they allowed us to analyze $\mathrm{Cre}$-recombination events.

In other experiments, Cre adenovirus treatment was repeated three times, so as to yield complete recombination. Before harvesting the latter cells, genotyping was performed to make sure that the $F n t b^{\text {lox/s}}$ cells had been converted to the $F n t b^{\Delta / \Delta}$ genotype. In some experiments, fibroblasts were treated with a protein farnesyltransferase inhibitor (FTI) (ABT-100, $5 \mu \mathrm{M}$ ) (Ferguson et al. 2005).

\section{RT-PCR reactions}

RT-PCR products were obtained from $F n t b^{\text {lox }}$ and $F n t b^{\Delta}$ alleles with exon1/exon5, exon1/exon8, and exon1/ exon4 primer sets. Exon 1 forward primer: $5^{\prime}$-TACAG CGCTCGCAGCTCTCC-3'; exon 5 reverse primer: $5^{\prime}$ CATTGACGGCTGCATAAGTG-3'; exon 8 reverse primer: $5^{\prime}$-GCCAAGCCACAGAAGGTGTA-3'); exon 4 reverse primer: $5^{\prime}$-CTGCTACTGGATCCTGCAC A-3'. Total RNA was extracted from MEFs or tissues with the RNeasy Mini kit (Qiagen); reverse transcriptase reactions were carried out with $500 \mathrm{ng}$ of RNA that had been treated with DNase (DNA-Free, Ambion), 
Superscript III (Invitrogen), and a mixture of oligo-dT (Invitrogen) and random primers (Invitrogen). The thermal cycling conditions were as follows: $95^{\circ} \mathrm{C}$ for $3 \mathrm{~min}, 95^{\circ} \mathrm{C}$ for $15 \mathrm{~s}, 60^{\circ} \mathrm{C}$ for $30 \mathrm{~s}$, and $72^{\circ} \mathrm{C}$ for $15 \mathrm{~s}$, for a total of 26 cycles.

\section{Western blots}

Cell extracts were electrophoresed on 4-12\% gradient polyacrylamide Bis-Tris gels (Invitrogen), and the proteins were electrophoretically transferred to a nitrocellulose membrane for western blotting. The antibody dilutions were 1:400 for anti-lamin $\mathrm{A} / \mathrm{C}$ goat IgG (sc-6215, Santa Cruz Biotechnology), 1:500 for anti-HDJ-2 mouse IgG (NeoMarkers), and 1:1000 for anti-actin goat IgG (sc-1616, Santa Cruz Biotechnology). After washing the membrane, the blots were incubated with secondary antibodies (1:5000 IRDye 700 anti-goat IgG antibody and 1:5000 IRDye 800 anti-mouse IgG antibody). Signals were detected with the Odyssey infrared imaging system (LI-COR Biosciences).

\section{Results and discussion}

We generated $F n t b^{\text {lox/A}}$ MEFs and incubated them with Cre adenovirus (Anton and Graham 1995) or an adenovirus encoding $\beta$-galactosidase. As expected, the floxed segment of DNA (spanning exon 3) was removed by Cre recombinase (Fig. 1a, b). The location of the loxP sites in the Fntb ${ }^{\text {lox }}$ allele was documented by DNA sequencing. As noted earlier, the excision of exon 3 was predicted to yield a frameshift (Mijimolle et al. 2005). To characterize the transcripts from the mutant allele, we performed RT-PCR reactions spanning sequences encoded by exons 1-5 and exons 1-8 (Fig. 2a-c). Following the excision of exon 3 from the genomic DNA, exon 4 was skipped by the mRNA splicing machinery. Thus, the predominant transcript from the $F n t b^{\Delta}$ allele in $F n t b^{\text {lox/A }}$ MEFs lacked exon 3 and exon 4 sequences (Fig. 2b, c). After a single round of Cre adenovirus infection, the amount of " $\Delta$ exon 3-4 transcript" was substantial, but some non-recombined (wild-type) transcripts remained (Fig. 2b). To achieve complete recombination, we treated $F n t b^{\text {lox/A}}$ MEFs with three rounds of $\mathrm{Cre}$ adenovirus (Fig. 2c). In the latter cells, none of the wild-type Fntb transcript remained.

The identity of the RT-PCR product corresponding to the " $\Delta$ exon 3-4 transcript" was confirmed by DNA sequencing (Fig. 2d). The $\Delta$ exon 3-4 transcript was the predominant transcript from the $F n t b^{\Delta}$ allele within the tissues of $F n t b^{\text {lox/ }}$ mice (Fig. 2e). The $\Delta$ exon 3-4 transcript is predicted to encode a protein with an in-frame deletion of amino acids 70-124.

As judged by ethidium bromide-stained agarose gels of RT-PCR reactions, the levels of the $\Delta$ exon 3-4 transcript in $F n t b^{\text {lox/A }}$ MEFs and mouse tissues were comparable to those of the wild-type Fntb transcript (Fig. 2b, c, e). Finding high levels of the $\Delta$ exon 3-4 transcript was not surprising because the $\Delta$ exon $3-4$ transcript lacks a premature stop codon and would not be subject to nonsense-mediated mRNA decay.

Trace amounts of a $\Delta$ exon 3 RT-PCR product could be detected between the wild-type and $\Delta$ exon 3-4 RT-PCR products (Fig. 2b, e). The identity of the $\Delta$ exon 3 RT-PCR product was confirmed by DNA
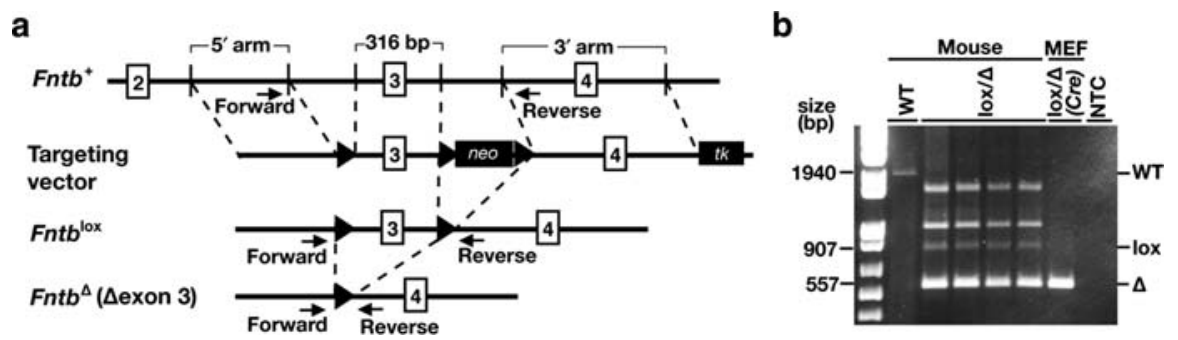

Fig. 1 A conditional knockout allele for Fntb, the gene encoding the $\beta$-subunit of FTase. a Strategy of Mijimolle et al. 2005 to create a conditional Fntb knockout allele. Cremediated excision of the floxed DNA segment removes exon 3 , a deletion that was predicted to yield a frameshift. b PCR strategy to genotype mice or mouse embryonic fibroblasts.
The PCR product yielded a 1,940-bp fragment from the wild-type Fntb allele, a 907-bp fragment from the $F n t b^{\text {lox }}$ allele, and a 557-bp fragment from the $F n t b^{\Delta}$ allele. The two extra bands, with apparent lengths of $\sim 1,100$ and 1,800 bp, are heteroduplexes 
a

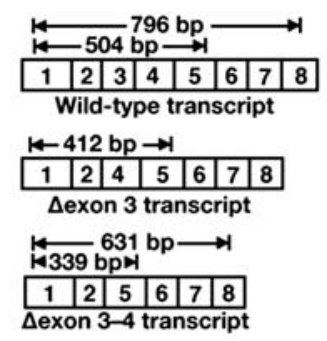

b

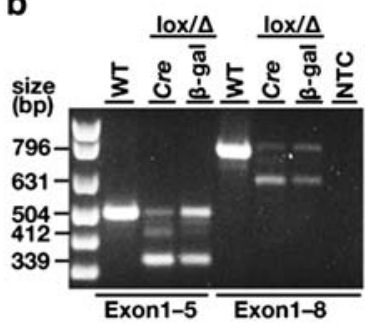

C

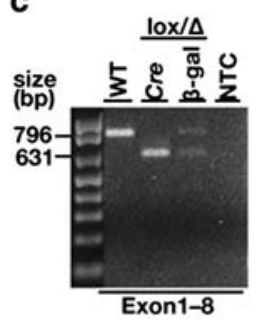

d

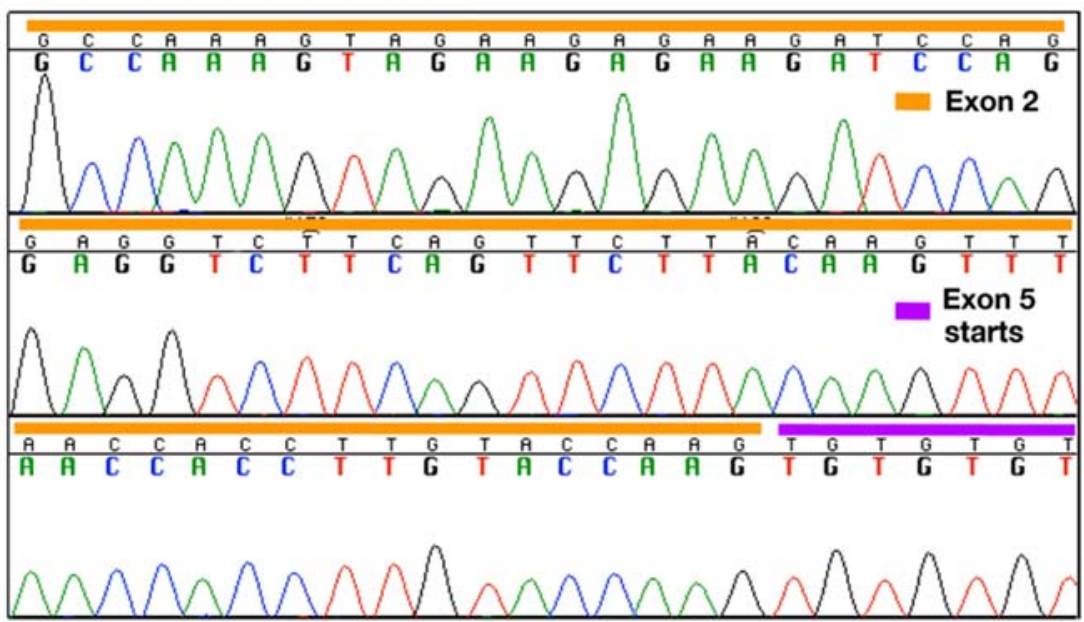

e

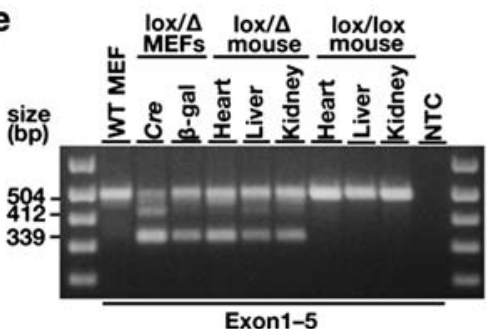

f

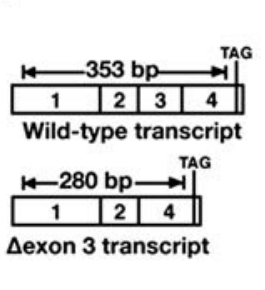

g

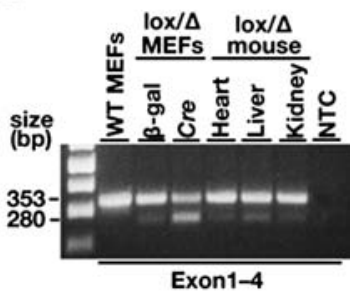

Fig. 2 Characterizing transcripts from the $F n t b^{\Delta}$ allele. a Schematic illustrating RT-PCR products obtained from $F n t b^{\text {lox }}$ and $F n t b^{\Delta}$ alleles with an exon1/exon5 primer set and an exon1/ exon8 primer set. b Ethidium bromide-stained $1.5 \%$ agarose gel showing the RT-PCR products generated from RNA prepared from wild-type (WT) MEFs, $\beta$-galactosidase adenovirus-treated

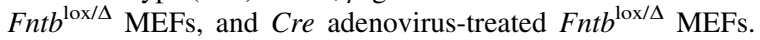
With the exon1/exon 5 primer set, the fainter amplicon between the 504-bp wild-type Fntb RT-PCR product and the 339-bp $\Delta$ exon 3-4 RT-PCR product is the 412-bp $\Delta$ exon 3 RT-PCR product. The numbers on the left indicate sizes of the RT-PCR products. $\mathbf{c}$ Ethidium bromide-stained $1.5 \%$ agarose gel showing the RT-PCR products (with the exon1/exon8 primer set) with RNA from wild-type (WT) MEFs and $F n t b^{\text {lox/ } / \Delta}$ MEFs that had been treated three times over 7 days with $\beta$-galactosidase adenovirus and $\mathrm{Cre}$ adenovirus. The RT-PCR reaction yields a 796-bp wild-type band and a 631-bp " $\Delta$ exon 3-4" product. The numbers on the left indicate sizes of the RT-PCR products. $\mathbf{d}$ DNA sequencing chromatogram showing the sequence of the $\Delta$ exon 3-4 RT-PCR product. The DNA fragment that was sequenced and purified from the agarose gel with the QIAquick Gel Extraction Kit (Qiagen). e Ethidium bromide-stained agarose gel showing the RT-PCR products generated from the exon1/exon5 primer set and RNA from Fntb ${ }^{\text {lox/ }}$ MEFs, the tissues of an $F n t b^{\text {lox/A}}$ mouse, and tissues of an $F n t b^{\text {lox/lox }}$ mouse. The predominant products were the 504-bp wild-type Fntb RT-PCR product and the 339-bp $\Delta$ exon 3-4 RT-PCR product. The numbers on the left indicate sizes of the RT-PCR products. $f$ Schematic illustrating RT-PCR products obtained from $F n t b^{\text {lox }}$ and $F n t b^{\Delta}$ alleles with an exon1/exon4 primer set. g Ethidium bromide-stained agarose gel showing the RT-PCR products generated from the exon1/exon4 primer set and RNA prepared from WT MEFs, $\beta$-galactosidase adenovirus-treated $F n t b^{\text {lox/ } / \Delta}$ MEFs, $C r e$ adenovirus-treated $F n t b^{\text {lox/ } / \Delta}$ MEFs, and tissues of an $F n t b^{\text {lox/A }}$ mouse. A strong 353-bp WT RT-PCR product and a fainter 280-bp $\Delta$ exon 3 RT-PCR product could be detected in

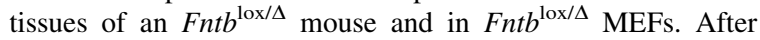
treating the cells with $C r e$ adenovirus, the $\Delta$ exon 3 RT-PCR product was more intense. The numbers on the left indicate sizes of the RT-PCR products 
sequencing (not shown). The $\Delta$ exon 3 transcript could also be detected by RT-PCR with an exon1/ exon4 primer set (this primer set cannot detect the $\Delta$ exon 3-4 transcript) (Fig. 2f, g). The level of the $\Delta$ exon 3 transcript, relative to the wild-type transcript, was low (Fig. 2b, e).

Prelamin A and HDJ-2 are both CaaX proteins that are farnesylated by FTase. In Cre adenovirus-treated $F n t b^{\text {lox/A }}$ MEFs (three rounds of infection), we found that HDJ-2 prenylation was blocked by only $50 \%$ (Fig. 3a). These results were essentially identical to the findings reported earlier by Mijimolle et al. (2005); they had produced $F n t b^{\Delta / \Delta}$ fibroblasts from a single cell clone and found that only $\sim 50 \%$ of HDJ-2 prenylation was blocked. In control experiments with wild-type fibroblasts, we found that a pharmacologic inhibitor of FTase blocked almost all HDJ-2 farnesylation (Fig. 3a).

We also found small amounts of prelamin A accumulation in these cells, indicating a partial blockade of lamin A biogenesis (Fig. 3b). Normally, prelamin A is efficiently converted to mature lamin A and prelamin A is virtually undetectable in cells. In the absence of farnesylation, prelamin A cannot be converted to mature lamin $\mathrm{A}$ and nonfarnesylated prelamin A accumulates in cells. Interestingly, the amount of prelamin A in $\mathrm{Cre}$ adenovirus-treated $F n t b^{\text {lox/A }}$ MEFs was small but increased when the cells were treated with an FTI (Fig. 3b). The existence

a

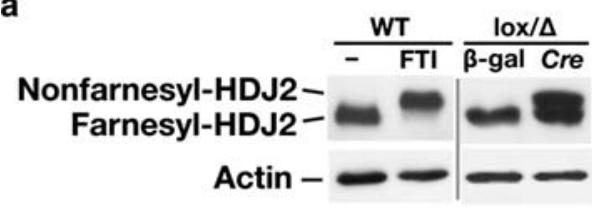

b

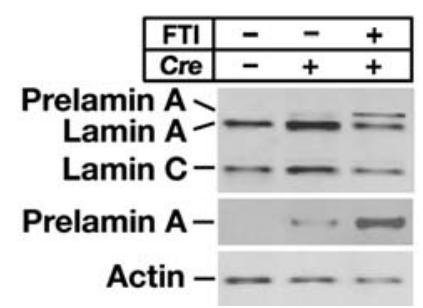

Fig. 3 Western blot analysis of wild-type (WT), $F n t b^{\text {lox/ } / \Delta}$, and Fntb ${ }^{\text {lox/ }}$ MEFs that had been treated with $C r e$ adenovirus or an FTI (ABT-100, $5 \mu \mathrm{M})$. a Western blots for HDJ-2; the slower migrating protein is nonfarnesylated HDJ-2. b Western blot for lamins $\mathrm{A} / \mathrm{C}$ and prelamin $\mathrm{A}$ in the presence and absence of a specific FTI (ABT-100, $5 \mu \mathrm{M})$ of nonfarnesylated HDJ-2 and prelamin A in Cre adenovirus-treated $F n t b^{\text {lox/A}}$ MEFs provided unequivocal evidence for markedly reduced FTase activity. On the other hand, the effects of the Fntb gene inactivation on HDJ-2 prenylation and lamin A biogenesis were less than we would have expected with a complete Fntb knockout. Also, we observed greater inhibition of HDJ-2 prenylation when Cre adenovirus-treated $F n t b^{\text {lox/A }}$ MEFs were treated with an FTase inhibitor (Toth et al. 2005; Yang et al. 2005).

At this point, we do not know if a mutant $\beta$-chain lacking amino acids 70-124 would be able to associate with the $\alpha$-chain and yield an FTase complex with residual enzymatic activity. However, this possibility is not farfetched; deletions of $>100$ amino acids from the amino terminus of the $\beta$-subunit of yeast FTase do not prevent association with the $\alpha$-chain (Urano et al. 2000). We also do not know if the internally truncated $\beta$-chain would yield a prenyltransferase with altered specificities. Addressing these issues with biochemical studies would be extremely challenging. In fact, we believe that biochemical experiments to fully exclude trace amounts of residual FTase activity from Mijimolle's $F n t b^{\Delta}$ allele (and biochemical experiments to unequivocally prove that the prenylation in $F n t b^{\Delta / \Delta}$ cells is due to geranylgeranyltransferase, type I) would be virtually impossible and ultimately would yield murky results.

In some knockout experiments, a 99.5\%-complete knockout might be entirely satisfactory. However, when the goal is to investigate the physiologic importance of FTase, a "leaky" knockout allele is suboptimal. When faced with an in-frame deletion and the possibility of an enzyme with partial function, one should strongly consider generating a new conditional knockout allele.

In constructing their conditional Fntb knockout allele, Mijimolle et al. (2005) reported that they had deleted $967 \mathrm{bp}$ of intron 2 and $297 \mathrm{bp}$ of intron 3 . Based on their paper, the intron 2 deletion started $114 \mathrm{bp} 5^{\prime}$ to the intron $2-$ exon 3 junction, and the intron 3 deletion started 146 bp $3^{\prime}$ to the exon 3-intron 3 junction. These descriptions did not match our DNA sequencing data; the deletions started $155 \mathrm{bp} 5^{\prime}$ and $88 \mathrm{bp} 3^{\prime}$ to exon 3 . We believe that introducing deletions this close to intron-exon junctions is hazardous, and we would not be surprised if the intron deletions contributed to the aberrant mRNA splicing. In any case, we suspect that the aberrant splicing event 
in Mijimolle's Fntb allele would have been overlooked by many laboratories. Conditional knockout alleles are almost always well characterized at the genomic DNA level, and the excision of an exon is widely regarded as proof of a null allele. The transcripts from knockout alleles are often not characterized, even when experimental findings raise the possibility of a leaky allele (Mijimolle et al. 2005).

The NIH has funded the Knockout Mouse Project (KOMP) to create a toolbox of mutant mouse alleles for the biomedical research community (Collins et al. 2007a, b). Thousands of conditional knockout alleles are now being generated. KOMP investigators introduce a $\operatorname{lox} P$ site and a "splice acceptor-lac $Z$ reporter cassette" into one intron and a second loxP site into another intron (Collins et al. 2007b). The initial targeting event yields a knockout allele containing a $\beta$-galactosidase reporter. However, the lac $Z$ cassette (which is flanked by FRT sites) can be excised with Flp recombinase, creating a conditional knockout allele in which an exon(s) is flanked by loxP sites (i.e., an allele that is structurally similar to the one created by Mijimolle et al. 2005). The studies reported here suggest that caution is warranted with conditional knockout alleles. In experiments with these alleles, whether they are obtained from KOMP or elsewhere, it is important to consider the possibility of unexpected splicing events. This is particularly important for any project where the creation of a true null allele is deemed important.

Acknowledgments This study was supported by an Ellison Medical Foundation Senior Scholar Award and National Institutes of Health (NIH) Grants HL76839, CA099506, and AR050200 (to S.G.Y), and HL086683 (to L.G.F). The Fntb mutant mice were obtained from Dr. Mariano Barbacid (Spain). ABT-100 was obtained from Dr. David Frost (Abbott Laboratories). S.H.Y. was supported by a Beginning Grant-in-Aid from the American Heart Association, Western States Affiliate.

Open Access This article is distributed under the terms of the Creative Commons Attribution Noncommercial License which permits any noncommercial use, distribution, and reproduction in any medium, provided the original author(s) and source are credited.

\section{References}

Anton M, Graham FL (1995) Site-specific recombination mediated by an adenovirus vector expressing the Cre recombinase protein: a molecular switch for control of gene expression. J Virol 69:4600-4606
Barrington RE, Subler MA, Rands E, Omer CA, Miller PJ, Hundley JE, Koester SK, Troyer DA, Bearss DJ, Conner MW et al (1998) A farnesyltransferase inhibitor induces tumor regression in transgenic mice harboring multiple oncogenic mutations by mediating alterations in both cell cycle control and apoptosis. Mol Cell Biol 18:85-92

Berzat AC, Buss JE, Chenette EJ, Weinbaum CA, Shutes A, Der CJ, Minden A, Cox AD (2005) Transforming activity of the Rho family GTPase, Wrch-1, a Wnt-regulated $\mathrm{Cdc} 42$ homolog, is dependent on a novel carboxyl-terminal palmitoylation motif. J Biol Chem 280:33055-33065. doi:10.1074/jbc.M507362200

Berzat AC, Brady DC, Fiordalisi JJ, Cox AD (2006) Using inhibitors of prenylation to block localization and transforming activity. Methods Enzymol 407:575-597. doi: 10.1016/S0076-6879(05)07046-1

Casey PJ, Seabra MC (1996) Protein prenyltransferases. J Biol Chem 271:5289-5292. doi:10.1074/jbc.271.10.5289

Chenette EJ, Abo A, Der CJ (2005) Critical and distinct roles of amino- and carboxyl-terminal sequences in regulation of the biological activity of the Chp atypical Rho GTPase. J Biol Chem 280:13784-13792. doi:10.1074/jbc.M411300200

Collins FS, Finnell RH, Rossant J, Wurst W (2007a) A new partner for the international knockout mouse consortium. Cell 129:235. doi:10.1016/j.cell.2007.04.007

Collins FS, Rossant J, Wurst W (2007b) A mouse for all reasons. Cell 128:9-13. doi:10.1016/j.cell.2006.12.018

Ferguson D, Rodriguez LE, Palma JP, Refici M, Jarvis K, O'Connor J, Sullivan GM, Frost D, Marsh K, Bauch J et al (2005) Antitumor activity of orally bioavailable farnesyltransferase inhibitor, ABT-100, is mediated by antiproliferative, proapoptotic, and antiangiogenic effects in xenograft models. Clin Cancer Res 11:3045-3054. doi: 10.1158/1078-0432.CCR-04-2041

Hasty P, Abuin A, Bradley A (2000) Gene targeting, principles, and practice in mammalian cells. In: Joyner A (ed) Gene targeting, a practical approach. Oxford University Press, Oxford

Kühn R, Schwenk F, Aguet M, Rajewsky K (1995) Inducible gene targeting in mice. Science 269:1427-1429. doi: 10.1126/science.7660125

Mijimolle N, Velasco J, Dubus P, Guerra C, Weinbaum CA, Casey PJ, Campuzano V, Barbacid M (2005) Protein farnesyltransferase in embryogenesis, adult homeostasis, and tumor development. Cancer Cell 7:313-324. doi: 10.1016/j.ccr.2005.03.004

Omer CA, Chen Z, Diehl RE, Conner MW, Chen HY, Trumbauer ME, Gopal-Truter S, Seeburger G, Bhimnathwala $\mathrm{H}$, Abrams MT et al (2000) Mouse mammary tumor virus$\mathrm{Ki}$-ras $\mathrm{B}$ transgenic mice develop mammary carcinomas that can be growth-inhibited by a farnesyl:protein transferase inhibitor. Cancer Res 60:2680-2688

Rajewsky K, Gu H, Kühn R, Betz UAK, Müller W, Roes J, Schwenk F (1996) Conditional gene targeting. J Clin Invest 98:600-603. doi:10.1172/JCI118828

Schwenk F, Baron U, Rajewsky K (1995) A cre-transgenic mouse strain for the ubiquitous deletion of $\operatorname{lox} P$-flanked gene segments including deletion in germ cells. Nucleic Acids Res 23:5080-5081. doi:10.1093/nar/23.24.5080

Takahashi K, Nakagawa M, Young SG, Yamanaka S (2005) Differential membrane localization of ERas and Rheb, 
two Ras-related proteins involved in the phosphatidylinositol 3-kinase/mTOR pathway. J Biol Chem 280:3276832774. doi:10.1074/jbc.M506280200

Todaro GJ, Green H (1963) Quantitative studies of the growth of mouse embryo cells in culture and their development into established lines. J Cell Biol 17:299-313. doi: 10.1083/jcb.17.2.299

Toth JI, Yang SH, Qiao X, Beigneux AP, Gelb MH, Moulson CL, Miner JH, Young SG, Fong LG (2005) Blocking protein farnesyltransferase improves nuclear shape in fibroblasts from humans with progeroid syndromes. Proc
Natl Acad Sci USA 102:12873-12878. doi:10.1073/pnas. 0505767102

Urano J, Yang W, Tamanoi F (2000) Mutational analyses of protein farnesyltransferase. Enzymes 21:47-80

Yang SH, Bergo MO, Toth JI, Qiao X, Hu Y, Sandoval S, Meta M, Bendale P, Gelb MH, Young SG et al (2005) Blocking protein farnesyltransferase improves nuclear blebbing in mouse fibroblasts with a targeted Hutchinson-Gilford progeria syndrome mutation. Proc Natl Acad Sci USA 102:10291-10296. doi:10.1073/pnas.0504641102 